\title{
The Experimental Measurements of Total Mass Attenuation Coefficients in Arsenic Oxide
}

\author{
B. Vasundhara, P. Tejeswararao \\ Department of Engineering Physics, GITAM Institute of Technology, GITAM University, Visakhapatnam, India \\ Email: b.vasun@gmail.com, teja_msc_phy@yahoo.co.in
}

Received 21 March 2016; accepted 6 July 2016; published 9 July 2016

Copyright $@ 2016$ by authors and Scientific Research Publishing Inc.

This work is licensed under the Creative Commons Attribution International License (CC BY).

http://creativecommons.org/licenses/by/4.0/

(c) (i) Open Access

\begin{abstract}
Measurements of $\mathrm{K}$-shell mass attenuation coefficients are reported for the first time in Arsenic oxide $\left(\mathrm{As}_{2} \mathrm{O}_{3}\right)$. Experiments are performed using Arsenic Oxide extended range HPGe detector. To achieve measurements at many small and regular energy intervals, secondary X-ray emission technique using "Seventeen Scatters" is employed. The results are in agreement with the proposed theoretical estimates. No evidence could, however be gained in favor of microscopic theories such as RRS and EXAFS, insofar as there are no energy points within a range of $100 \mathrm{eV}$ on either side of the K-edge.
\end{abstract}

\section{Keywords}

Mass Attenuation, Arsenic Oxide, K-Shell, Energy Intervals

\section{Introduction}

There are some but not specific measurements tabulated on the energy range dependence of k-shell mass attenuation — sections in the element, with which this research has identified. Along with the common notion that Arsenic is a highly poisonous substance, it needs to be understood that this element pertains to the low energy region of $5 \mathrm{KeV}$ to $17 \mathrm{KeV}$ and covers K-edge of arsenic which is pegged at $11.867 \mathrm{KeV}$. This data is important not only because it provides much needed experimental values but also assimilates the phenomena of anomalous $\mathrm{X}$-ray scattering near the k-edge of the element. To do such an investigation, it is of primary importance to have experimental data close to the K-edge in regular intervals with a short magnitude. This research asserts that this is not possible even by applying radioactive sources as is normally done. This research therefore argues that characteristic X-rays produced by secondary excitation in suitable neighboring elements, namely $\mathrm{Cr}, \mathrm{Mn}, \mathrm{Fe}, \mathrm{Co}$, 
Ni, Cu, Zn, Ge, Se, Br, Sr and Y, have all been used for the measurement of total mass attenuation coefficients.

\section{Experimentation}

The experimental arrangement is illustrated in Figure 1. The primary source $\mathrm{R}$, which is a strong $\mathrm{Pu}^{238} \mathrm{point}^{\mathrm{in}}$ source of $10 \mathrm{mci}$, is properly shielded to allow controlled X-rays to interface on the selected scatter, S. The characteristic X-rays from the scatters route through a Compton shield circular slit and then through the absorber film of Arsenic oxide and two more circular slits (filters) to reach the detector stationed in a lead box, this box shields the detector from unwanted radiation emitted if any from other origin(S).

The detector used is an extended range HpGe detector with a low energy cut-off at $3 \mathrm{KeV}$ and has an energy range of Max $1000 \mathrm{KeV}$ and with $5 \mathrm{Mil}$ Beryllium windows. The energy resolution of the detector is locked at $200 \mathrm{eV}$ and at $5.9 \mathrm{KeV}$.

\subsection{Axioms Description}

Referencing the absorber foil preparation, the required thickness for the $\mathrm{As}_{2} \mathrm{O}_{3}$ compound was deposited on a Watt Man no. 1 filter paper discs in the prefixed energy range namely 5 to $18 \mathrm{KeV}$. The compound thickness under investigation for transmission between one per cent and ten per cent is estimated using an analysis of the total cross-section's from the tabulations of Scofield tables. The thickness of the applied absorbers ranges from 3 $\mathrm{mg} / \mathrm{cm}^{2}$ to $200 \mathrm{mg} / \mathrm{cm}^{2}$ to facilitate compound preparation within the walls of the absorber.

\subsection{Protocols Description}

For absorber preparation, filter paper technique as described by Sharanabasappa et al. (2010) [1] is applied. These experimental absorbers are prepared by creating a circular hallow of $1 \mathrm{~cm}$ diameter in three cello phone rings attached one over the other on a cello-phone sheet and covered on the dorsal side also with the same cellophone sheet after depositing the $\mathrm{As}_{2} \mathrm{O}_{3}$ compound uniformly, inside the created hallow. The absorber so prepared is held firmly stretched amidst two thin "Mylar Rings" to be positioned vertically within the experimental arrangement.

The Uniformity of compound deposition is again tested using the X-Ray transmission methodology. Arsenic Oxide absorber was found to be undisturbed as it was uniformly distributed throughout the experiment because of Arsenic's dynamic and inherent characteristics associated to its surface tension and its thickness. The mass attenuation coefficient is obtained from the formula.

$$
\mu / r=L_{n}\left\{I_{o} / I\right\}
$$

where $I_{o}$ is the intensity, $L_{n}$ is the transmission intensity, $\rho$ is the density of mass and $x$ is the thickness obtained from the mass " $m$ " and area " $a$ " of the liquid film as

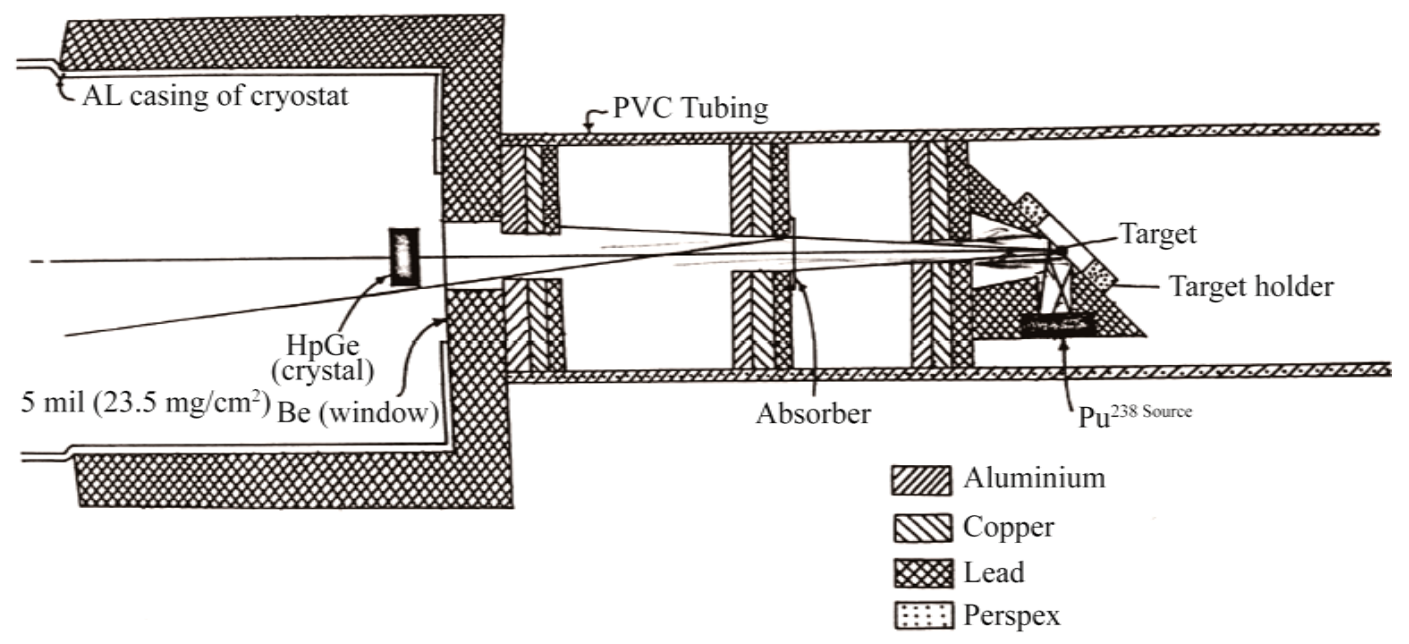

Figure 1. Geometrical set-up showing Detector, Absorber, Exciter and Primary sources with graded stilts. 


$$
x \rho=m / a .
$$

The experimental mass attenuation coefficients of Arsenic Oxide are measured at eighteen energy points in the low energy region of 5 to $17 \mathrm{KeV}$. The elemental mass attenuation coefficients are deduced based on Sum-Rule and are compared with previous research works with a limitation of data availability.

Reemphasizing that Arsenic is a highly poisonous substance and that there are no earlier measurements of total photon attenuation coefficients in this element at any photon energy, it needs to be mentioned that special care had to be exercised in preparing the targets and iterating the target etc., because of its highly poisonous nature to human beings. The present composition of the compound Arsenic Oxide $\left(\mathrm{As}_{2} \mathrm{O}_{3}\right)$ is a weighted contribution of Arsenic at 75 per cent and Oxygen at 25 per cent by weight to the molecular weight of the total compound. As said, "Sum-rule" is applied to derive the experimental mass-attenuation coefficient of Arsenic from those of the compound and one presented in Table 1 at eighteen energy points in the range of $5 \mathrm{KeV}$ to $17 \mathrm{KeV}$. It needs to be observed from Table 1 that out of these eighteen energies, eleven energies remain below the K-edge, while the remaining seven energies lie above the K-edge (The K-edge energy being $11.867 \mathrm{KeV}$ ). The mass attenuation coefficients of element Arsenic are determined assuming the Sum-Rule to be valid even in this energy region also.

\section{Data Analysis and Interpretation}

Column 3 in Table 1 provides the theoretical estimates of mass attenuation coefficients derived from the total photon attenuation cross-section obtained by combining the photo electric cross-sections of Scofield [2] coherent and incoherent scattering cross-sections of Hubbel [3] and Hubbell \& Overbo [4] respectively.

Table 1. Measured total photon mass-attenuation coefficient element arsenic compared with theoretical and semi-empirical values.

\begin{tabular}{|c|c|c|c|c|c|}
\hline \multirow[b]{2}{*}{ Energy $(\mathrm{KeV})$} & \multirow[b]{2}{*}{ Experimental values } & \multicolumn{2}{|c|}{$\begin{array}{l}\text { Theoretical values of Scofield + Hubble } \\
\text { + Hubble \& Overbo }\end{array}$} & \multicolumn{2}{|c|}{ Victoreen et al. } \\
\hline & & Values & Deviation (\%) & Values & Deviation (\%) \\
\hline 5.411 & $222.17 \pm 3.99$ & 218.89 & 1.5 & 231.61 & 4.00 \\
\hline 5.895 & $175.72 \pm 3.17$ & 173.64 & 1.2 & 181.73 & 3.20 \\
\hline 6.404 & $140.40 \pm 2.54$ & 138.74 & 1.2 & 143.50 & 2.00 \\
\hline 6.925 & $113.64 \pm 2.05$ & 112.19 & 1.3 & 115.31 & 1.40 \\
\hline 7.472 & $92.49 \pm 2.78$ & 91.22 & 1.4 & 92.35 & 0.15 \\
\hline 8.041 & $76.19 \pm 1.38$ & 75.22 & 1.3 & 74.73 & 1.90 \\
\hline 8.631 & $62.28 \pm 1.13$ & 61.55 & 1.2 & 60.92 & 2.20 \\
\hline 9.572 & $45.76 \pm 0.83$ & 46.41 & 1.4 & 45.15 & 1.30 \\
\hline 9.876 & $43.20 \pm 0.82$ & 42.65 & 1.3 & 41.30 & 4.90 \\
\hline 10.986 & $32.33 \pm 0.59$ & 31.86 & 1.5 & 30.26 & 6.80 \\
\hline 11.210 & $30.64 \pm 0.58$ & 30.10 & 1.8 & 28.54 & 7.30 \\
\hline 11.907 & $191.42 \pm 3.34$ & 177.57 & 7.8 & 174.26 & 9.80 \\
\hline 12.502 & $158.71 \pm 2.86$ & 156.83 & 1.2 & 154.91 & 2.40 \\
\hline 13.299 & $135.59 \pm 2.46$ & 133.85 & 1.3 & 133.13 & 1.80 \\
\hline 14.142 & $112.48 \pm 2.03$ & 114.20 & 1.5 & 114.12 & 1.40 \\
\hline 140933 & $100.63 \pm 1.82$ & 99.14 & 1.4 & 99.30 & 1.30 \\
\hline 15.859 & $85.28 \pm 1.54$ & 84.19 & 1.2 & 85.11 & 0.20 \\
\hline 16.766 & $74.17 \pm 1.35$ & 73.15 & 1.4 & 73.63 & 0.76 \\
\hline
\end{tabular}


It may be seen from Table 1, that the errors associated with the present experimental attenuation coefficients are less than 2.00 per cent. These errors include statistical error of 0.5 per cent at the maximum and 1.00 per cent due to other effects such as the dead time correction, error in estimation of mass of the absorber and error due to a possible impurity of the element. This research is one of the first pioneering works to feature a distribution of $\mathrm{K}$-edge values above and below the $\mathrm{KeV}$. Of the eighteen energies, eleven energies fall below the K-edge, while the remaining seven energies are above the K-edge, the K-edge energy being pegged at $11.867 \mathrm{KeV}$. The mass attenuation coefficients of the element Arsenic are determined assuming the "Sum-Rule" to be valid in this energy region. This is the positive proof for the validity of "Sum-rule" even in this low energy region. It may also, be noticed from Table 1, that as the values move closer to the K-edge on either side the deviations from theory are quite large compared to the experimental error. The above assertion is a point to focus attention, on the basis of the prediction due to R.R.S., EXAFS and XANES. There are two energy points above the K-edge within the range of $1 \mathrm{KeV}$, one being very close at just $40 \mathrm{eV}$, while the other being located at $635 \mathrm{eV}$. Notably, the measured value at the first point at $40 \mathrm{eV}$ from the edge deviates by a large span of 7.8 per cent the second point which is a bit further away at $635 \mathrm{eV}$ from the edge and is in satisfactory agreement with the theoretical value with a negligible percentage deviation of 1.2 per cent.

This feature suggests that the large deviation of the first data point renders support to the theoretical predictions due to EXAFS and/or XANES, in that their range of manifestation from the K-edge is rather short and will die away even at a distance $635 \mathrm{eV}$ from the K-edge, hence proving that these are highly localized effects and may manifest very close to the K-edge within an energy range of a few $100 \mathrm{eV}$. There are two energy points within $1 \mathrm{KeV}$ below the K-edge, namely $10.986 \mathrm{KeV}$ and $11.21 \mathrm{KeV}$ which are respectively at $881 \mathrm{eV}$ and 635 eV below the K-edge.

From Table 1 and Table 2 the total mass attenuation coefficients at these two points are quite in agreement with theory. Referring to the fact that there are no RRS effects at these points, it may be in lieu of the fact that

Table 2. Measured total photon mass-attenuation coefficient element arsenic compared with theoretical and semi-empirical values.

\begin{tabular}{|c|c|c|c|c|c|c|c|}
\hline \multirow[b]{2}{*}{ Energy $(\mathrm{KeV})$} & \multirow[b]{2}{*}{ Experimental values } & \multicolumn{2}{|c|}{ Power law } & \multicolumn{2}{|c|}{ Orlic et al. } & \multicolumn{2}{|c|}{ L. Gerward et al. } \\
\hline & & Values & Deviation (\%) & Values & Deviation (\%) & Values & Deviation (\%) \\
\hline 5.411 & $222.17 \pm 3.99$ & 218.92 & 1.5 & 219.20 & 1.30 & 226.48 & 1.90 \\
\hline 5.895 & $175.72 \pm 3.17$ & 173.85 & 1.0 & 173.92 & 1.10 & 179.43 & 2.10 \\
\hline 6.404 & $140.40 \pm 2.54$ & 139.13 & 0.9 & 138.94 & 1.10 & 143.13 & 1.90 \\
\hline 6.925 & $113.64 \pm 2.05$ & 112.96 & 0.6 & 112.50 & 1.00 & 115.77 & 1.80 \\
\hline 7.472 & $92.49 \pm 2.78$ & 91.97 & 0.5 & 91.35 & 1.24 & 93.83 & 1.40 \\
\hline 8.041 & $76.19 \pm 1.38$ & 75.47 & 0.9 & 74.74 & 1.90 & 76.61 & 0.50 \\
\hline 8.631 & $62.28 \pm 1.13$ & 62.40 & 0.2 & 61.59 & 1.10 & 62.99 & 1.10 \\
\hline 9.572 & $45.76 \pm 0.83$ & 47.27 & 3.0 & 46.43 & 1.40 & 47.29 & 3.20 \\
\hline 9.876 & $43.20 \pm 0.82$ & 4352 & 0.7 & 42.67 & 1.20 & 43.52 & 0.70 \\
\hline 10.986 & $32.33 \pm 0.59$ & 32.70 & 1.1 & 31.89 & 1.40 & 30.15 & 3.70 \\
\hline 11.210 & $30.64 \pm 0.58$ & 30.93 & 0.3 & 30.13 & 2.90 & 29.43 & 5.40 \\
\hline 11.907 & $191.42 \pm 3.34$ & 180.55 & 6.7 & 177.64 & 7.80 & 184.00 & 4.03 \\
\hline 12.502 & $158.71 \pm 2.86$ & 158.22 & 0.3 & 157.01 & 1.10 & 161.93 & 2.00 \\
\hline 13.299 & $135.59 \pm 2.46$ & 133.84 & 1.3 & 134.12 & 1.10 & 137.63 & 1.40 \\
\hline 14.142 & $112.48 \pm 2.03$ & 113.33 & 1.2 & 114.15 & 1.40 & 117.01 & 3.80 \\
\hline 140933 & $100.63 \pm 1.82$ & 97.81 & 2.8 & 99.46 & 1.20 & 101.28 & 0.64 \\
\hline 15.859 & $85.28 \pm 1.54$ & 63.11 & 2.6 & 84.99 & 0.30 & 86.29 & 1.20 \\
\hline 16.766 & $74.17 \pm 1.35$ & 71.50 & 3.7 & 73.41 & 1.03 & 74.37 & 0.20 \\
\hline
\end{tabular}


they are quite far from the K-edge exceeding even the $500 \mathrm{eV}$ mark away from the K-edge. This fact again summarily asserts that the effects due to RRS will not be felt a few hundreds of $\mathrm{eV}$ away from the K-edge. Column 4 through 7 of Table 2, furnishes the semi-empirical predictions of different authors and describes along with the percentage deviation with the present experimental values.

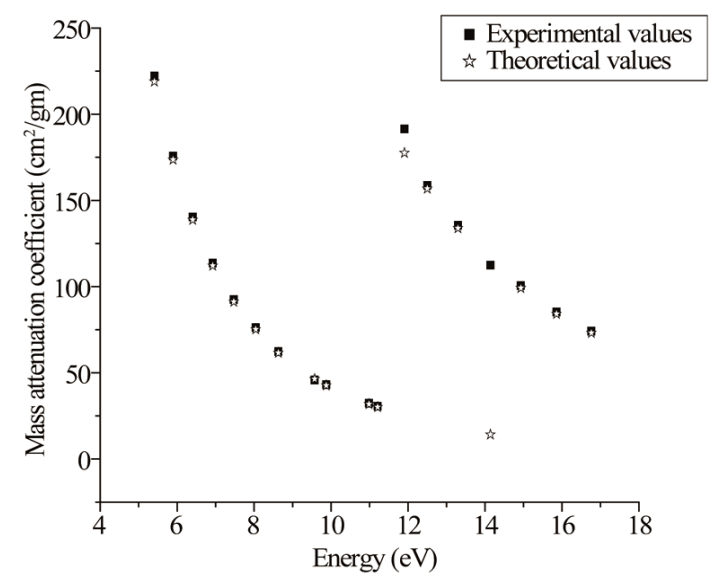

(a)

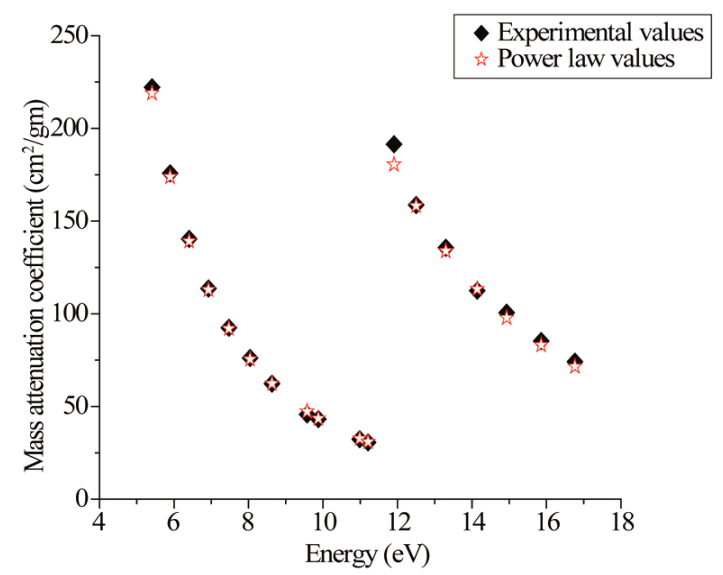

(c)

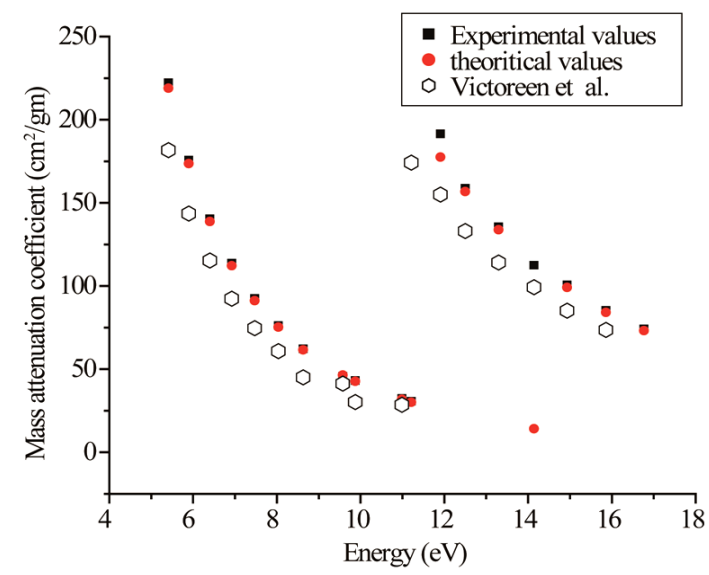

(b)

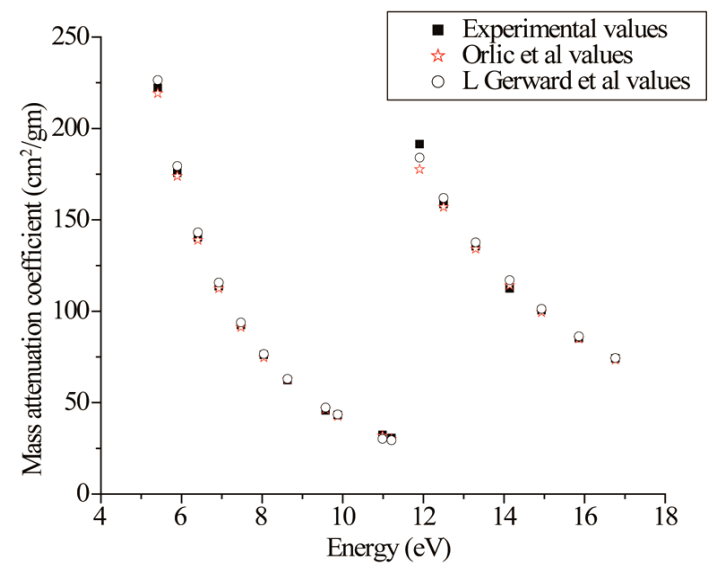

(d)

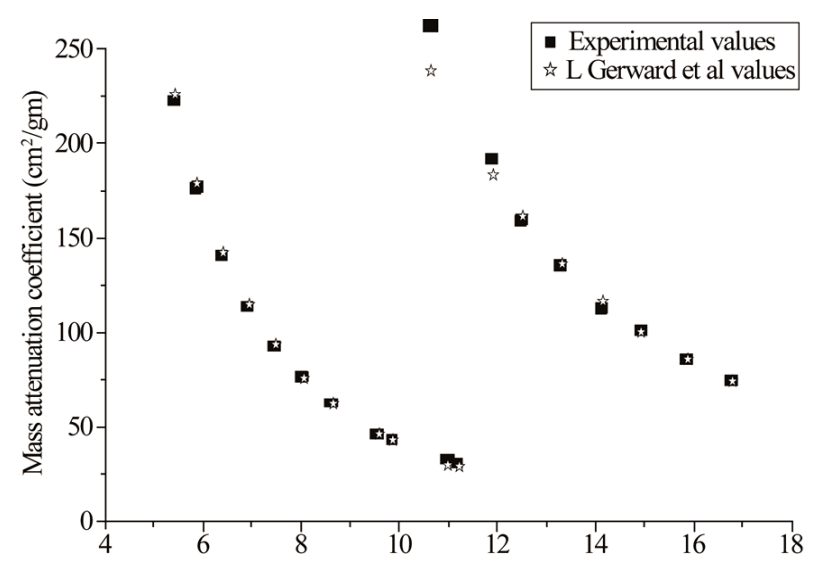

(e)

Figure 2. (a) Comparison of theoretical and experimental mass attenuation coefficient of arsenic; (b) Theoretical and experimental mass attenuation coefficient of arsenic with Victoreen's values; (c) Comparison of experimental mass attenuation coefficient of arsenic with power law; (d) Comparison of experimental mass attenuation coefficient of arsenic with Orlic's values; (e) Comparison of experimental mass attenuation coefficient of arsenic with L. Gerward's values. 
A critical examination of these semi-empirical values reflects that in Arsenic the values due to Ortic et al. are quite close to the experimental values, where as the values due to Gerward whose power law is supposed to be more refined taking into consideration the functional dependence on $\mathrm{Z}$ and $\mathrm{E}$ and the exponents are quite out of tune with the present experimental values with large percentage deviations. The values due to Victoreen, et al. are coinciding with the normal and deviate from the experimental values quite significantly. The values attributed to Power Law seem to fit the experimental values closely except at the edge and the three highest points in the chosen energy range. The semi-empirical scheme due to Orlic et al. [5], stands best in fitting the present experimental values while those due to the Simple Power Law seem to be the next best.

The predictions of the semi-empirical schemes are also given in graphical format in Figure 2(a) to Figure 2(e) each graph plotting the values due to one-semi-empirical scheme along with the experimental and theoretical values for close comparison. Figure 2(a) shows experimental values compared with the theoretical values alone. The values due to Victoreen are plotted in Figure 2(b). The values due to Power Law in Figure 2(c) those due to Orlic et al. [5] are plotted in Figure 2(d) those values due to the improved Power Law of Gerward are plotted in Figure 2(e).

\section{Conclusions}

There are no earlier experimental measurements on the mass attenuation coefficients in this element within the energy range or even outside a given range. The present investigations reveal that the predictions of the edge effects due to RRS, EXAFS and XANES are more significant in higher $Z$ group elements.

The results of this research show and re-emphasize the primary importance of having experimental data close to the K-edge in regular intervals with a short magnitude and assert that characteristic X-rays produced by secondary excitation in suitable neighboring elements, namely $\mathrm{Cr}, \mathrm{Mn}, \mathrm{Fe}, \mathrm{Co}, \mathrm{Ni}, \mathrm{Cu}, \mathrm{Zn}, \mathrm{Ge}, \mathrm{Se}, \mathrm{Br}, \mathrm{Sr}$ and $\mathrm{Y}$ can be used for the measurement of total mass attenuation coefficients.

\section{References}

[1] Sharanabasappa, Kerur, B.R., Anilkumar, S. and Hanumaiah, B. (2010) Determination of X-Ray Mass Attenuation Coefficients Using HPGe Detector. Applied Radiation and Isotopes, 68, 76-83. http://dx.doi.org/10.1016/j.apradiso.2009.08.004

[2] Saloman, E.B., Hubbell, J.H. and Scofield, J.H. (1988) X-Ray Attenuation Cross Sections for Energies $100 \mathrm{eV}$ to 100 $\mathrm{KeV}$ and Elements $\mathrm{Z}=1$ to $\mathrm{Z}=92$. Atomic Data and Nuclear Data Tables, 38, 1-196. http://dx.doi.org/10.1016/0092-640X(88)90044-7

[3] Hubbell, J.H. (1982) Photon Mass Attenuation and Energy-Absorption Coefficients. The International Journal of Applied Radiation and Isotopes, 33, 69-1290. http://dx.doi.org/10.1016/0020-708X(82)90248-4

[4] Hubble, J.H. and Overbo, I. (1979) Relativistic Atomic Form Factors and Photon Coherent Scattering Cross Sections Journal of Physical and Chemical Reference Data, 8, 69. http://dx.doi.org/10.1063/1.555593

[5] Orlic, I., Loh, K.K., Sow, C.H., Tang, S.M. and Thong, P. (1993) Parametrization of the Total Photon Mass Attenuation Coefficients in the Energy Range 0.1 - $1000 \mathrm{KeV}$. Nuclear Instruments and Methods in Physics Research Section B: Beam Interactions with Materials and Atoms, 74, 352-361. http://dx.doi.org/10.1016/0168-583X(93)95964-7 


\section{Submit or recommend next manuscript to SCIRP and we will provide best service for you:}

Accepting pre-submission inquiries through Email, Facebook, LinkedIn, Twitter, etc.

A wide selection of journals (inclusive of 9 subjects, more than 200 journals)

Providing 24-hour high-quality service

User-friendly online submission system

Fair and swift peer-review system

Efficient typesetting and proofreading procedure

Display of the result of downloads and visits, as well as the number of cited articles

Maximum dissemination of your research work

Submit your manuscript at: http://papersubmission.scirp.org/ 